\title{
Can it wait? A systematic review of immediate vs. delayed surgical repair of penile fractures
}

\author{
Nathan Colin Wong, MD; Shawn Dason, MD; Rahul K. Bansal, MBBS, MS, MCh; Timothy O. Davies, MD; \\ Luis H. Braga, MD
}

Division of Urology, McMaster University, Hamilton, ON, Canada

Cite as: Can Urol Assoc J 2017;11 (1-2):53-60. http://dx.doi.org/10.5489/cuaj.4032

\section{Abstract}

Introduction: Penile fractures have classically been thought to require immediate surgical intervention; however, recent series have described acceptable outcomes with delayed repair. In this systematic review, we compared complication rates between immediate and delayed repair of penile fractures.

Methods: A systematic search of MEDLINE, Embase, CENTRAL, and Web of Science was performed with predefined search terms between 1974 and 2015. Titles and abstracts were screened prior to full-text review and quality appraisal by two independent investigators. Abstracted outcomes included postoperative erectile dysfunction (ED), tunical scar formation, and penile curvature. Only studies reporting a direct comparison of complications following immediate $(<24$ hours from injury to presentation/surgery) and delayed ( $>24$ hours) repair of penile fractures were included.

Results: A total of 12 studies met inclusion criteria. All were retrospective, observational studies of low or moderate methodological quality. Of the reported 502 patients, 391 underwent immediate repair and 111 delayed repair. In the immediate repair group, the percent of patients with postoperative ED, tunical scars, and curvature were $6.6 \%, 5.4 \%$, and $1.8 \%$, respectively, while in the delayed group, the rates of ED, tunical scars, and curvature were $4.5 \%$ across the board. Rates of ED and tunical scar formation following immediate compared to delayed repair trended towards favouring immediate repair, but did not differ significantly, while rates of curvature significantly favoured immediate repair. However, cases of curvature were typically reported as mild and none affected sexual functioning.

Conclusions: In this systematic review, we demonstrated that ED and tunical scar formation rates between immediate and delayed repair of penile fractures were statistically similar, while immediate repair had a lower rate of penile curvature. Although this suggests that a brief delay in repair may be acceptable in select patients, the results should be interpreted with caution, as the included studies were of low or moderate methodological quality. Most importantly, this review highlights the deficiencies in the current penile fracture literature, setting the stage to improve the quality of future studies.

\section{Introduction}

Penile fractures are classically recognized as a urological emergency requiring immediate surgical intervention. Penile fractures occur after traumatic rupture of the tunica albuginea of one or both corpora cavernosa, typically when the penis is erect during rigorous sexual activity, masturbation, or penile manipulation. ${ }^{1}$ At the time of injury, patients often describe an audible snap, followed immediately by penile detumescence and pain. Immediate surgical repair is the current standard of care with lower risks of complications, including erectile dysfunction (ED), penile curvature, and tunical scar formation, compared to conservative management. ${ }^{1,2}$

In a retrospective study by Yamicake et al, 42 patients with penile fracture presented over an eight-year period to their centre, with 35 managed surgically and six conservatively. ${ }^{2}$ Fewer complications were seen with patients managed surgically, with $88.6 \%$ reporting sufficient erections for intercourse with no voiding dysfunction or penile curvature compared to $66.7 \%$ of those managed conservatively. Thus, surgical repair showed clear benefits over conservative management and this has been confirmed in other studies.

Although immediate surgery is advocated, timing of penile fracture repair can either be early (less than 24 hours from injury to presentation/surgery) or delayed (greater than or equal to 24 hours). Delayed repair of penile fracture may occur due to delayed presentation after initial injury, surgeon preference, or in patients who initially select conservative management. From a logistical perspective, a delayed repair may allow for the case to be deferred to a more specialized surgeon with more experience of the relevant anatomy, as well as minimized disruption to surgeon and hospital scheduling. ${ }^{1}$ A delay may allow for medical optimization of the patient prior to surgery, reduced tissue edema, and the demarcation of healthy and necrotic tissue. Further, preoperative imaging with ultrasound or magnetic resonance imaging (MRI) may allow for a reduction in negative explorations and more precise planning of the repair. ${ }^{3}$ 
Karadeniz et $\mathrm{al}^{4}$ and Gottenger and Wagner ${ }^{5}$ reported that the delay between injury and surgery was linked to higher rates of complications. Alternatively, Zargooshi performed a large, retrospective analysis in which patients were treated with surgical repair regardless of any delay in presentation..$^{6,7}$ With delayed presentation, he found there were no further difficulties in identifying the injury site and no increased rates of complications, including ED. He commented that there is no need to perform immediate repair and cases may be safely deferred until the next morning. Kozacioglu et al further investigated whether a delay in time until surgery had an effect to the overall long-term results of penile fracture repair. ${ }^{8}$ They categorized a total of 56 patients who underwent penile fracture repair based on the time from trauma to surgery into three groups: $0-6$ hours, 6.1-12 hours, and greater than 12 hours. They found that postoperative International Index of Erectile Function (IEF) questionnaires between all groups were statistically similar. They concluded that surgical repair had good functional outcome and neither serious deformity, nor ED occurred as a result of short delays in surgical repair in patients with no associated urethral injuries.

Nonetheless, it is currently uncertain if delays in repair offer similar long-term patient outcomes. Given the uncertainty, we conducted a systematic review and meta-analysis to examine the effect of immediate vs. delayed surgical repair of penile fractures on postoperative ED, tunical scarring, and penile curvature formation.

\section{Methods}

\section{Identification of pertinent studies}

Relevant articles were identified via a systematic search of MEDLINE, Embase, and Cochrane Central Register of Controlled Trials (CENTRAL) between 1974 and 2015. A gray literature search of conference abstracts was also performed using Web of Science. Additional references were included from the reference lists of relevant articles. The search strategy was created a priori and reviewed with a medical librarian to ensure comprehensiveness. Searches used a combination of keywords and $\mathrm{MeSH}$ headings related to penile injuries and penile fractures (Appendix A).

\section{Screening and assessing for eligibility}

Title and abstract screening was conducted independently by two investigators to select all citations that could potentially meet predetermined eligibility criteria. Duplicate studies were removed. Screened citations were selected for full-text review. During full-text review, studies were judged for inclusion in the final analysis based on predetermined eligibility criteria. Discrepancies were resolved by consensus with the inclusion of a third investigator. Investigators were not blinded, as concealment has previously not been found to have a significant effect on the final results of systematic reviews. ${ }^{9}$

\section{Eligibility criteria}

Predetermined criteria for study inclusion consisted of: 1) focus on humans; 2) language limited to English, French, Italian, and Portuguese studies; 3 ) penile fracture as primary diagnosis; 4) studies including direct comparison of immediate (less than 24 hours from time of injury to presentation/ surgery) vs. delayed surgical repair (greater than or equal to 24 hours); 5) sample sizes greater than or equal to two in each group; 6) reporting of postoperative complications; and 7) clinical research designation. All primary study types were included in the review and no age restrictions were used.

\section{Assessment of methodological quality}

Critical appraisal of the included studies was carried out by two independent reviewers using a quality assessment instrument adopted from Wright et al and modified to fit the objectives of this study. ${ }^{10}$ All discrepancies were resolved through third-party review of the methodology. Studies were assigned a value of 1 or 0 based on the presence or absence of the following criteria: prospective study, clearly stated objective, consecutive patients, single-centre study, use of rigorous statistical evaluation (including presence of $\mathrm{p}$ value), and complete followup with no patients lost to followup during the study period. Articles scoring 0-2 points were deemed low-quality, 3-4 points intermediate-quality, and 5-6 points high-quality.

\section{Data extraction}

Data extraction was completed in duplicate. When data was unclear or missing from the article, attempts were made to contact study authors. Extraction fields were defined a priori and included the age of patients, time from injury to surgery, complications, and duration of followup.

\section{Outcome measures}

The primary outcome measured in all included studies was the development of postoperative complications, in particular ED, following surgical repair of penile fractures. Tunical scar formation and penile curvature were diagnosed in most articles and analyzed when reported. Complications were considered to be present for a given subject if they met the criteria put forth by the article from which they were drawn. 


\section{Statistical analyses}

Meta-analysis was performed with the Mantel-Haenszel method to calculate odds ratio (OR), random effects model, $\mathrm{p}<0.05$ for significance, 0.5 zero-cell correction, and $95 \%$ confidence interval $(\mathrm{Cl})$ for complication as primary outcome measure. Comprehensive Meta-Analysis version 2.2.064 (Biostat, Englewood, NJ, U.S.) was used for metaanalysis. An a priori decision was made to use the random effects model for meta-analysis to account for between-study heterogeneity, as all studies were retrospective and observational. Heterogeneity between studies was tested using the Cochran chi-square $\mathrm{Q}$ test with a $\mathrm{p}$ value set at 0.1 and quantified using the $\mathrm{I}^{2}$ statistic. A funnel plot was used to assess publication bias.

\section{Results}

A total of 1941 potentially relevant citations were initially retrieved, decreasing to 1236 when duplications were removed (Fig. 1). After title and abstract screening, 151 articles were selected for full-text review. Full-text review and application of eligibility criteria led to exclusion of 139 studies, leaving 12 for inclusion in this systematic review. 2,3,8,11-19 All included articles were retrospective, observational studies. Six articles were assessed to be of moderate quality, while the other six were low quality, as per our quality assessment instrument described above (Table 1).

The total number of patients included in the analysis was 502 (391 in the immediate repair group and 111 in the

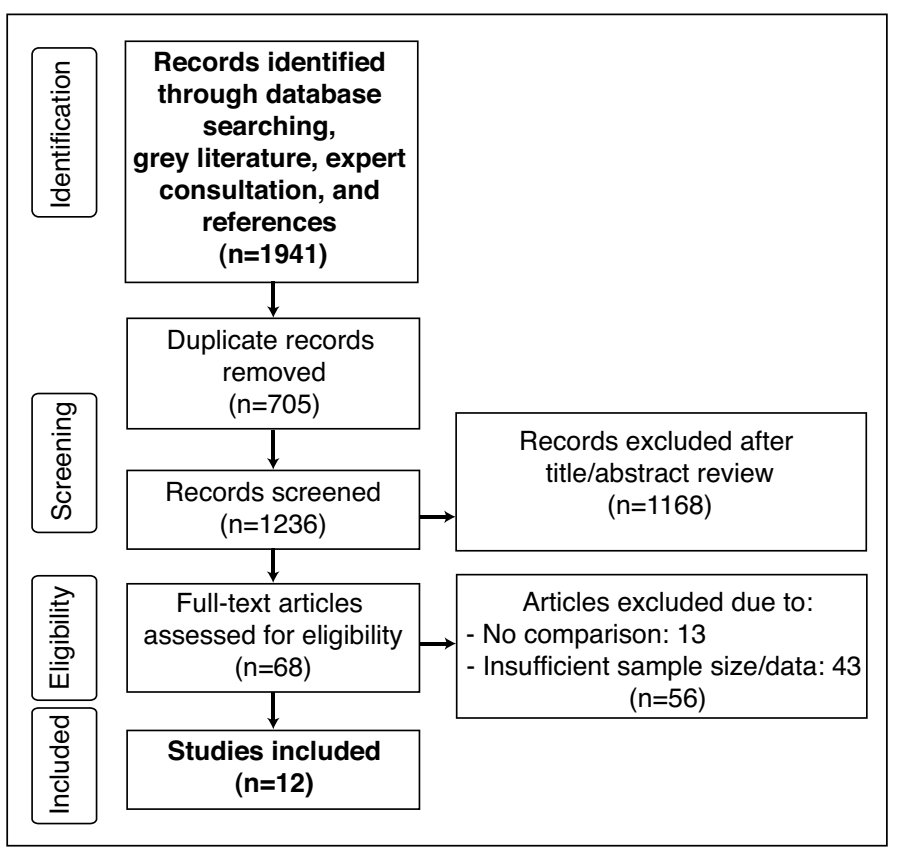

Fig. 1. PRISMA flow diagram of literature search and study selection for systematic review and meta-analysis. delayed repair group). Demographic data, study information, and complications of the included studies are presented in Table 2. The mean age among the included studies ranged from 26.4-40.8 years, with an average followup of 17.3 months. The mean ages in the immediate and delayed groups were 34.0 and 33.1 years, respectively. The delayed group had a mean time to presentation/surgery ranging from 29.3 hours-16 days.

ED, our primary outcome of interest, was present in the immediate and delayed groups in $6.6 \%$ and $4.5 \%$, respectively. The rate of ED following immediate repair compared to delayed repair slightly favoured immediate repair, but did not differ significantly, as shown in Fig. 2A (OR 0.58, 95\% Cl $0.24-1.37 ; p=0.213)$. A subsequent subgroup analysis was performed for studies in which the sample sizes were $\geq 10$ in each group (Fig. 2B) that showed similar results with no statistically significant difference (OR $0.71,95 \% \mathrm{Cl} 0.24-2.08$; $\mathrm{p}=0.527$ ).

In our review, we made the assumption that articles which reported time to presentation were equivalent to time to surgery in the included meta-analysis. Realizing that this is not always the case, we performed a subgroup analysis of the seven series that specifically reported time from injury to time to surgery instead of time to presentation (Fig. 3). Similar results were obtained that favoured the early group, but similarly, there was no statistically significant difference for the development of ED between early and delayed repair (OR 0.50, 95\% Cl 0.16-1.60; $p=0.244$ ).

Tunical scar formation was present in the immediate and delayed group in $5.4 \%$ and $4.5 \%$, respectively. The rate of tunical scars following immediate repair compared to delayed repair also did not differ significantly (OR 0.59, 95\% Cl 0.18-1.98; $\mathrm{p}=0.393$ ) (Fig. 4). Alternatively, penile curvature was present in the immediate and delayed group in $1.8 \%$ and $4.5 \%$, respectively. In this case, the rate of penile curvature did significantly favour immediate repair (OR 0.33, 95\% Cl 0.12-0.92; p=0.034) (Fig. 5). None of the studies reported any life-threatening complications related to surgical repair in either group.

There was no significant statistical heterogeneity between the studies for either intervention with an $\mathrm{I}^{2}$ of $0.1 \%$. However, because of the retrospective design and heterogeneous cohorts of included studies, clinical heterogeneity was undoubtedly present. A funnel plot (Fig. 6) illustrates that there was minimal contribution of publication bias to the presented results.

\section{Discussion}

This systematic review identified only 12 studies addressing immediate (less than 24 hours from time of injury to presentation/surgery) and delayed (greater than or equal to 24 hours) repair of penile fractures with reported complica- 


\begin{tabular}{|c|c|c|c|c|c|c|c|}
\hline & $\begin{array}{l}\text { Prospective } \\
\text { study }\end{array}$ & $\begin{array}{c}\text { Clear } \\
\text { objective }\end{array}$ & $\begin{array}{c}\text { Consecutive } \\
\text { patients }\end{array}$ & Single-centre & $\begin{array}{l}\text { Statistical } \\
\text { evaluation }\end{array}$ & $\begin{array}{l}\text { Complete } \\
\text { followup }\end{array}$ & $\begin{array}{c}\text { Total criteria } \\
\text { met }(/ 6)\end{array}$ \\
\hline Anseimo $199^{11}$ & No & No & Yes & Yes & No & No & 2 \\
\hline Saporta $1996^{12}$ & No & No & Yes & Yes & No & No & 2 \\
\hline Cummings $1998^{13}$ & No & No & Yes & No & No & Yes & 2 \\
\hline Hsu $2002^{14}$ & No & Yes & Yes & No & No & No & 2 \\
\hline Shetty $2004^{16}$ & No & Yes & Yes & Yes & No & No & 3 \\
\hline Wani $2008^{15}$ & No & Yes & Yes & Yes & No & No & 3 \\
\hline Agarwal $2009^{3}$ & No & No & Yes & No & No & No & 1 \\
\hline El-Assmy $2011^{17}$ & No & Yes & Yes & Yes & Yes & No & 5 \\
\hline Kozaciglu $2011^{8}$ & No & Yes & No & Yes & Yes & Yes & 5 \\
\hline Alzubaidi $2012^{18}$ & No & Yes & No & Yes & No & Yes & 2 \\
\hline Tijani $2012^{19}$ & No & Yes & No & No & No & No & 1 \\
\hline Yamacake $2013^{2}$ & No & Yes & No & Yes & Yes & No & 3 \\
\hline
\end{tabular}

tions. Meta-analysis of these studies suggests that a delay in penile fracture repair leads to no significant difference —albeit non-statistically favouring immediate repair — in the rates of ED or formation of tunical scars at a mean followup of 17.3 months. Even within the subgroup analysis of limiting studies to sample size greater than 10 and limiting studies that directly report time from injury to time to surgery, similar results were obtained. Perhaps a larger sample size or greater patient numbers are required to demonstrate statistical significance for favouring early repair.
Nonetheless, with the current sample size, the rate of penile curvature was significantly lower for immediate repair compared to delayed. However, articles typically reported the cases of curvature as mild. As there were no severe cases and no reports of curvature that affected sexual functioning, penile curvature was felt to be clinically insignificant in the included series.

Similar to our results, Zargooshi reported no relationship between the delay to surgery and the development of complications, and found no increased difficulty with surgi-

\begin{tabular}{|c|c|c|c|c|c|c|c|c|c|}
\hline \multirow[t]{2}{*}{ Authors } & \multirow[t]{2}{*}{ Journal } & \multirow[t]{2}{*}{$\begin{array}{c}\text { Study } \\
\text { location }\end{array}$} & \multirow[t]{2}{*}{$\begin{array}{c}\text { Number } \\
\text { (early/delayed) }\end{array}$} & \multirow[t]{2}{*}{ Age } & \multirow[t]{2}{*}{$\begin{array}{c}\text { Time to } \\
\text { presentation or } \\
\text { surgery reported }\end{array}$} & \multicolumn{3}{|c|}{$\begin{array}{c}\text { Number of complications } \\
\text { (early/delayed) }\end{array}$} & \multirow[t]{2}{*}{ Followup } \\
\hline & & & & & & ED & Plaque & Curvature & \\
\hline $\begin{array}{l}\text { Anseimo } \\
1991^{11}\end{array}$ & Br J Urol & $\begin{array}{c}\text { Treviso, } \\
\text { Italy }\end{array}$ & $\begin{array}{c}13 \\
(10 / 3)\end{array}$ & $\begin{array}{c}39 \\
\text { (mean) }\end{array}$ & Surgery & $(0 / 0)$ & $(1 / 2)$ & $(0 / 1)$ & $\begin{array}{c}6 \text { months- } \\
8 \text { years (range) }\end{array}$ \\
\hline $\begin{array}{l}\text { Saporta } \\
1996^{12}\end{array}$ & Int Urol Nephrol & $\begin{array}{l}\text { Istanbul, } \\
\text { Turkey }\end{array}$ & $\begin{array}{c}11 \\
(9 / 2)\end{array}$ & $\begin{array}{c}22-39 \\
\text { (range) }\end{array}$ & Surgery & $(0 / 0)$ & $(0 / 1)$ & $(0 / 1)$ & 9 months \\
\hline $\begin{array}{l}\text { Cummings } \\
1998^{13}\end{array}$ & J Trauma & $\begin{array}{l}\text { St. Louis, } \\
\text { U.S. }\end{array}$ & $\begin{array}{c}10 \\
(7 / 3)\end{array}$ & $\mathrm{N} / \mathrm{A}$ & Surgery & $(0 / 0)$ & $(0 / 0)$ & $(0 / 0)$ & 6 months \\
\hline $\begin{array}{l}\text { Hsu } \\
2002^{14}\end{array}$ & J Urol & $\begin{array}{l}\text { Taipei, } \\
\text { Taiwan }\end{array}$ & $\begin{array}{c}11 \\
(8 / 3)\end{array}$ & $\begin{array}{c}30.4 \\
\text { (mean) }\end{array}$ & Presentation & $(0 / 0)$ & N/A & $\mathrm{N} / \mathrm{A}$ & 6 months \\
\hline $\begin{array}{l}\text { Shetty } \\
2004^{16}\end{array}$ & ANZ J Urol & $\begin{array}{l}\text { Belgaum, } \\
\text { India }\end{array}$ & $\begin{array}{c}7 \\
(2 / 5)\end{array}$ & $\begin{array}{c}22-36 \\
\text { (range) }\end{array}$ & Surgery & $(0 / 0)$ & N/A & $(0 / 2)$ & $\begin{array}{c}7 \text { weeks- } \\
2 \text { years (range) }\end{array}$ \\
\hline $\begin{array}{l}\text { Wani } \\
2008^{15}\end{array}$ & Oman Med Urol & $\begin{array}{l}\text { Kashmir, } \\
\text { India }\end{array}$ & $\begin{array}{c}52 \\
(19 / 33)\end{array}$ & $\mathrm{N} / \mathrm{A}$ & Presentation & $(0 / 0)$ & $\mathrm{N} / \mathrm{A}$ & $\mathrm{N} / \mathrm{A}$ & $\begin{array}{l}\text { 4-7 months } \\
\text { (range) }\end{array}$ \\
\hline $\begin{array}{l}\text { Agarwal } \\
2009^{3}\end{array}$ & Can J Urol & $\begin{array}{l}\text { Chandigarh, } \\
\text { India }\end{array}$ & $\begin{array}{c}14 \\
(11 / 3)\end{array}$ & $\begin{array}{c}27-72 \\
\text { (range) }\end{array}$ & Presentation & $(0 / 0)$ & $(0 / 0)$ & $(0 / 0)$ & 7.5 months \\
\hline $\begin{array}{l}\text { El-Assmy } \\
2011^{17}\end{array}$ & Urology & $\begin{array}{l}\text { Mansoura, } \\
\text { Egypt }\end{array}$ & $\begin{array}{c}180 \\
(149 / 31)\end{array}$ & $\begin{array}{c}35 \\
\text { (mean) }\end{array}$ & Presentation & $(9 / 2)$ & $(13 / 1)$ & $(5 / 3)$ & 106 months \\
\hline $\begin{array}{l}\text { Kozaciglu } \\
2011^{8}\end{array}$ & Urol Int & $\begin{array}{l}\text { Izmir, } \\
\text { Turkey }\end{array}$ & $\begin{array}{c}42 \\
(39 / 3)\end{array}$ & $\begin{array}{c}40.8 \\
\text { (mean) }\end{array}$ & Surgery & $(9 / 1)$ & $(4 / 0)$ & $(0 / 1)$ & $\begin{array}{l}46.1 \text { months } \\
\text { (mean) }\end{array}$ \\
\hline $\begin{array}{l}\text { Alzubaidi } \\
2012^{18}\end{array}$ & $\begin{array}{l}\text { J Sex Med } \\
\text { (podium) }\end{array}$ & $\begin{array}{l}\text { Doha, } \\
\text { Qatar }\end{array}$ & $\begin{array}{c}109 \\
(98 / 11)\end{array}$ & N/A & Surgery & $(4 / 2)$ & $N / A$ & $N / A$ & 3 months \\
\hline $\begin{array}{l}\text { Tijani } \\
2012^{19}\end{array}$ & Arab J Urol & $\begin{array}{l}\text { Lagos, } \\
\text { Nigeria }\end{array}$ & $\begin{array}{c}18 \\
(16 / 2)\end{array}$ & $\begin{array}{c}26.4 \\
\text { (mean) }\end{array}$ & Presentation & $(0 / 0)$ & $(0 / 0)$ & $(0 / 0)$ & 10 months \\
\hline $\begin{array}{l}\text { Yamacake } \\
2013^{2}\end{array}$ & KJU & $\begin{array}{c}\text { Sao Paulo, } \\
\text { Brazil }\end{array}$ & $\begin{array}{c}35 \\
(23 / 12)\end{array}$ & $\begin{array}{c}33.8 \\
\text { (mean) }\end{array}$ & Surgery & $(4 / 0)$ & $(3 / 0)$ & $(2 / 1)$ & $\begin{array}{l}14.5 \text { months } \\
\text { (mean) }\end{array}$ \\
\hline
\end{tabular}




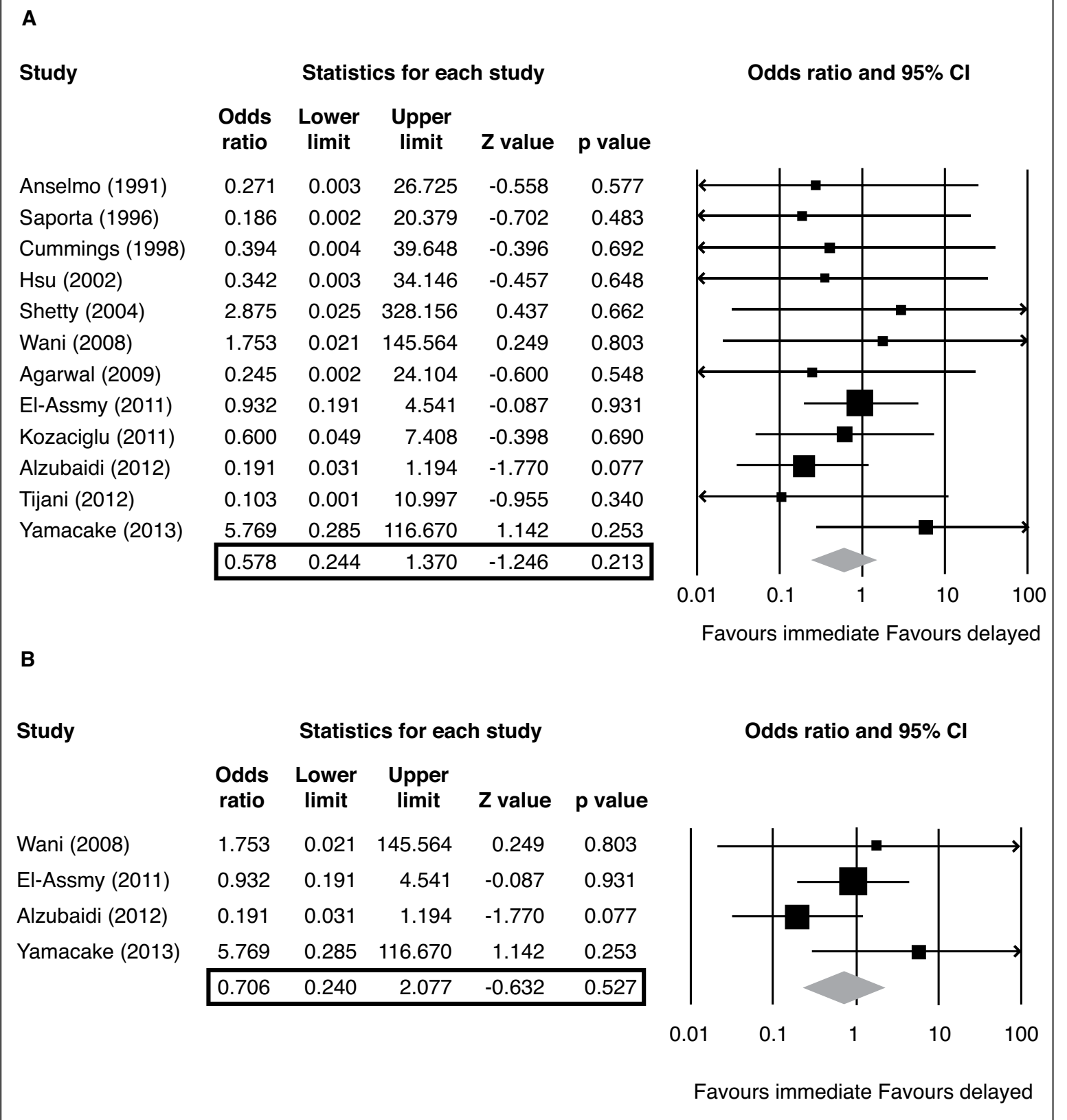

Fig. 2. Forest plots of postoperative erectile dysfunction of delayed and immediate repair of penile fractures. Sample size $(\boldsymbol{A}) \geq 2$; and $(\boldsymbol{B}) \geq 10$ patients in each of the immediate and delayed repair groups. Squares indicate means within individual series. Diamond indicates mean and range of all series.

cal dissection in an 18-year followup study of 352 patients with penile fracture who underwent surgical repair within 24 hours of admission, regardless of any delay in presentation. ${ }^{6,7,20}$ In this cohort, patients would undergo immediate surgery if the operating room was available; otherwise, the surgery would be delayed until the next morning. Of the 217 patients who had partners, $98.6 \%$ reported potency, with a mean IIEF ED domain score of $29.8 \pm 1.1$. As rates of ED were similar between patients who underwent immediate and delayed surgical repair, he concluded that surgery should be performed at the first convenient moment and there should be no emphasis on immediate repair.

Thus, while classical teaching suggests that immediate repair of penile fractures is warranted, our systematic review and meta-analysis suggests that a brief delay in repair may be acceptable, with similar complication rates to delayed repair. Delaying repair to the next day may allow for the case to be deferred to a more specialized surgeon with greater experience of the penile anatomy, for medical optimization of the patient prior to surgery, and for preoperative imaging to allow for more precise surgical repair.

Our study defined early repair as less than

24 hours and late repair as greater than 24 hours. We used these ranges, as they were the most common definitions within the available literature. It would, however, be ideal if we could further divide the time delays to less than 24 hours, 24-72 hours, 72 hours-one week and greater than one week. Unfortunately, even when we attempted to contact the authors of the articles, the majority of raw data, including the exact timing of injury to repair, was unavailable and thus we were unable to perform this analysis.

Several papers that evaluated delays in repair only, without reporting any cases of immediate repair, were not included in our meta-analysis. Nasser and Mostafa reported 24 patients 
Wong et al.

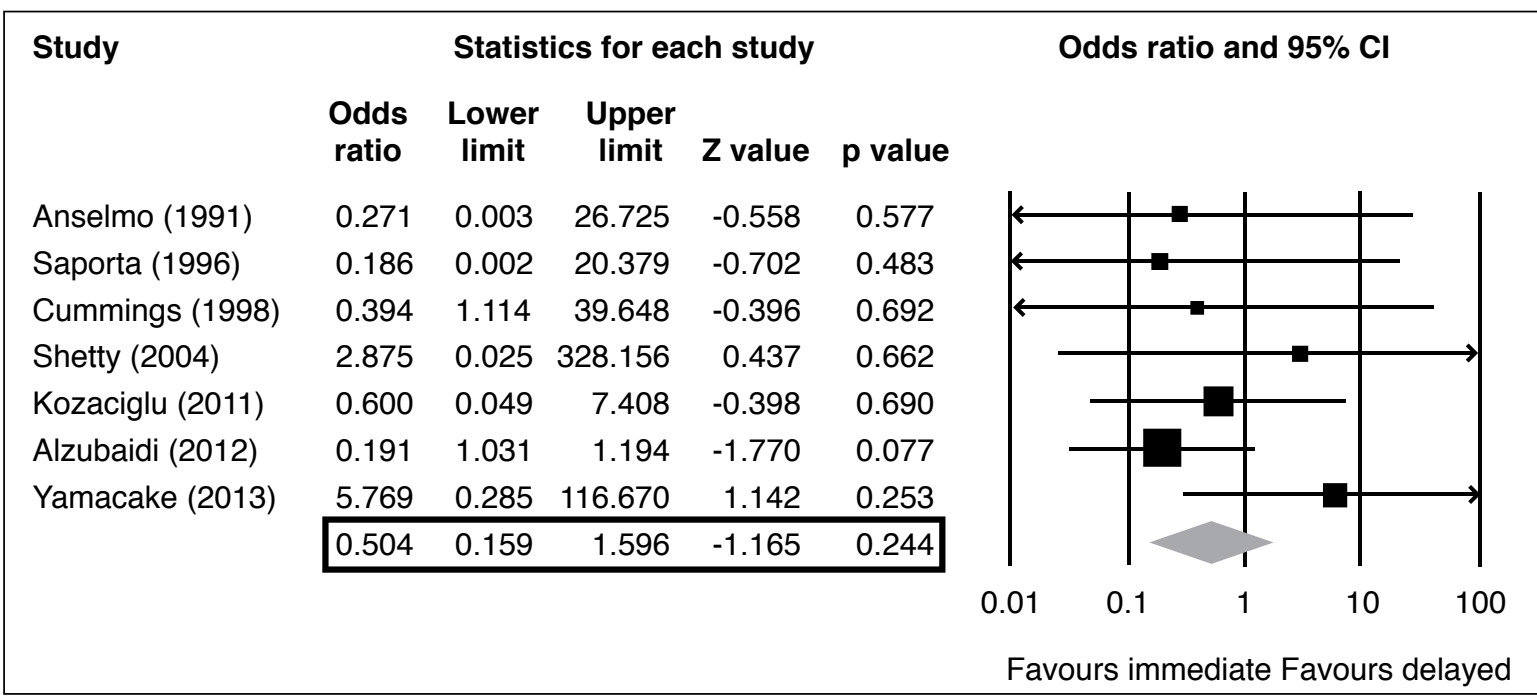

Fig. 3. Forest plots of postoperative erectile dysfunction of delayed and immediate repair of penile fractures, including only series directly reporting time from injury to surgery. Squares indicate means within individual series. Diamond indicates mean and range of all series. within 36 hours and seven after 36 hours. $^{23}$ All of the patients who underwent repair within 36 hours had good results, with normal erections and sexual life without the development of curvature. Alternatively, of the seven patients treated after 36 hours, only four had good results, with penile fractures who presented late and then subsequently subjected to conservative management for 7-12 days, followed by surgical repair. ${ }^{21}$ In their series, there were no intraoperative or postoperative complications encountered and all patients regained sexual activity 4-6 weeks after delayed repair. Similarly, Naraynsingh et al described three patients with penile fractures who initially had diffusely swollen penises. ${ }^{22}$ Treatment was delayed for 7-12 days to allow the swelling to subside, leaving only a lump of hematoma directly over the area of injury, facilitating easy identification of the torn corpus cavernosum and successful simple direct repair over the injury instead of a degloving technique. Kibria et al reported on 19 patients who underwent repair of penile fractures and used a definition of greater than 36 hours for delayed repair (instead of 24 hours in our meta-analysis); 12 had surgery

with no ED. The other three had fair results, with mild to moderate curvature, but still with no reported ED.

In our review, we limited our meta-analysis to publications that directly compared immediate vs. delayed repair within the same study, as patients would be expected to be evaluated in a similar manner, particularly in a singlecentre study. However, the findings of this review should be taken in the context of the data arising from retrospective, observational studies of low to moderate methodological quality and relatively small sample sizes due to the rarity of penile fractures.

There was also considerable inter-article variability when reporting complications. ED was determined from patient history from seven studies, while the rest were not specified. ${ }^{8,12,13,15-18}$ Only one study reported use of a standard-

\section{Odds ratio and $95 \% \mathrm{Cl}$}

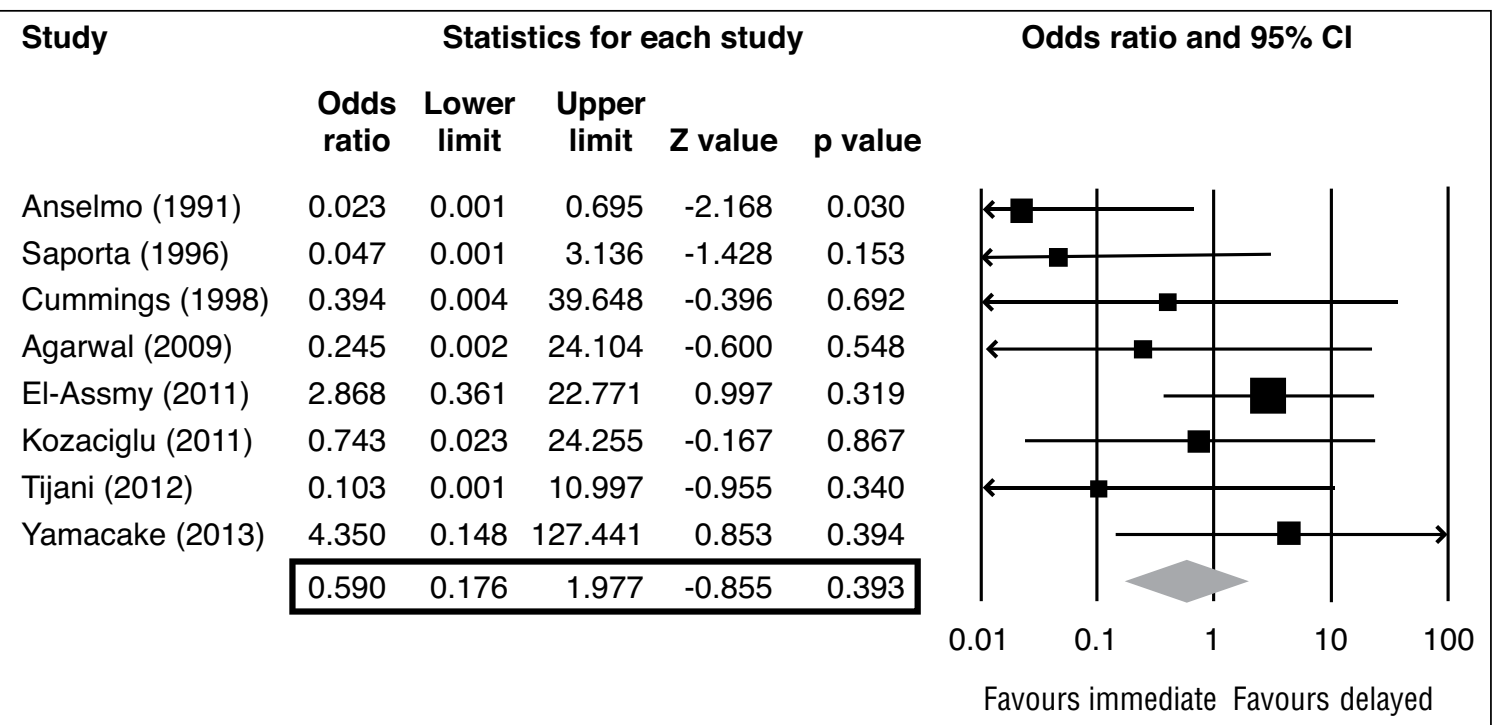

Fig. 4. Forest plot of postoperative penile plaque formation of delayed and immediate repair of penile fractures. Squares indicate means within series. Diamond indicates means and ranges within series. ized questionnaire - IIEF — to assess for ED and severity. ${ }^{8}$ Some of the other studies qualified the severity of complications as mild, moderate, and severe, but did not define these terms in the article. None of the studies quantified the size of tunical scars when present and none specified the degree of angulation when describing curvature. Some of the 


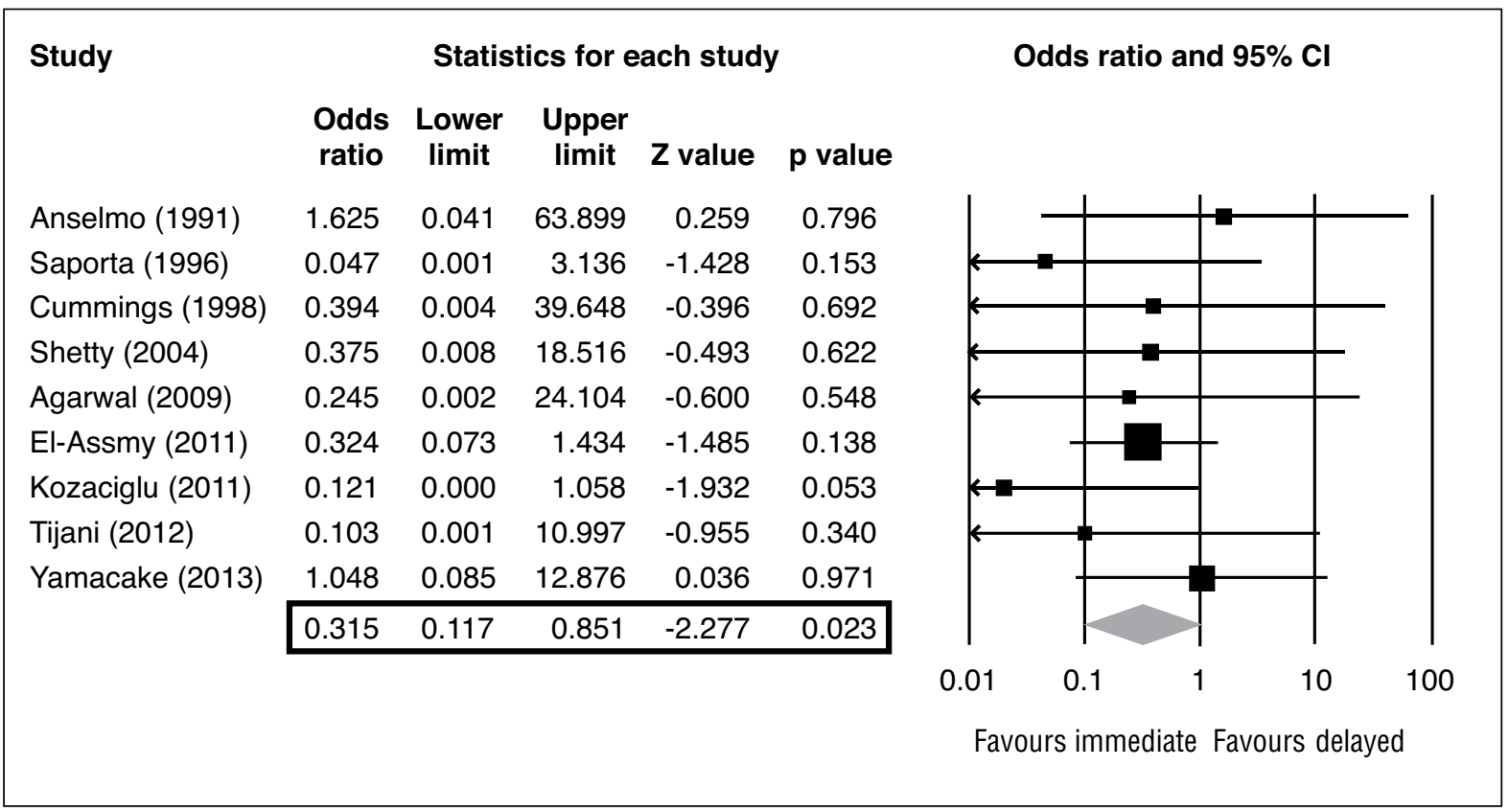

Fig. 5. Forest plot of postoperative penile curvature of delayed and immediate repair of penile fractures. Squares indicate means within individual series. Diamond indicates mean and range of all series.

studies did not comment on associated injuries, such as urethral injuries, which would be treated differently from isolated penile fractures. Thus, concomitant urethral injuries could not be evaluated in the meta-analysis and should be treated with immediate surgical repair.

The indications for delaying surgery, as well as the severity of fractures and associated complications, were also not clearly defined in all of the studies and were likely not uniform. Study findings may be biased if the time to repair in the included studies was a function of the severity of injury. Some patients with a "mild" penile fracture with no or minimal symptoms would present later and thus undergo a delayed repair compared to patients with "severe" fractures. Therefore, the "severe" penile fracture patients may have required earlier repair, leading to the observed equivalent complication rates for ED and tunical scar formation com-

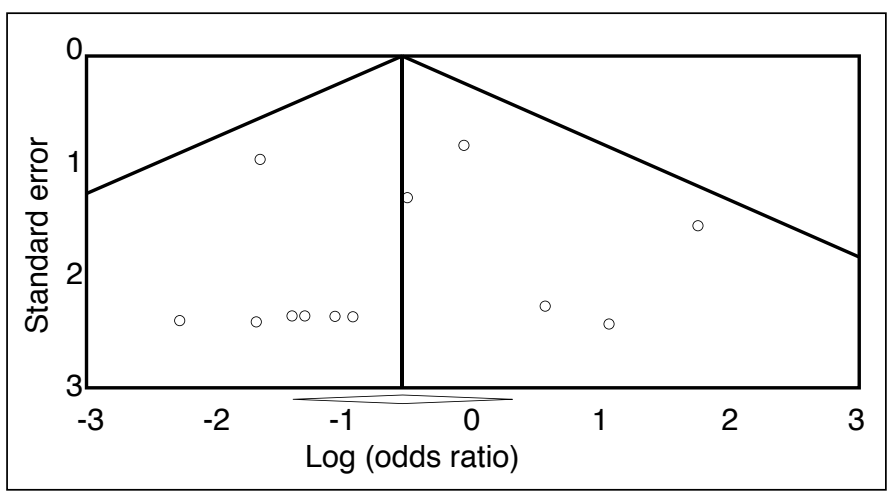

Fig. 6. Funnel plot of included studies comparing immediate vs. delayed repair of penile fractures. pared to the delayed group. Followup rates and protocols were generally inconsistent or not reported. Most studies had patients lost to followup and thus had incomplete followup within their cohort (Table 1). Assessment of complications of penile fracture was heterogeneous and most authors did not report their assessment methodology, let alone use standardized measurement scales.

Our results, like all systematic reviews, are compromised by the low to moderate methodological quality of the included studies and the results should be interpreted with caution. These results, however, provide important insights in the deficiencies in the penile fracture literature, setting the stage to improve the quality of future reporting. Penile fracture is a heterogenous diagnosis with sequelae that could be influenced by a number of factors. These include mechanism of injury, location and extent of injury, use of imaging modalities, timing and method of repair, and associated injuries. Reporting of penile facture sequelae is also rarely objective; and more objective measures and questionnaire responses should be included.

Reporting of penile fractures in future trials should include preoperative details of penile fractures, including time from injury to presentation, unilateral or bilateral disease, location, length of injury, and associated injuries, in particular urethral involvement. Use of any preoperative imaging and findings should also be reported. Further, operative details of the procedures should also be reported, including time from injury to surgery, type of incision (degloving vs. direct), type of closure, and suture type. Finally, future studies should aim to report objective postoperative outcome measures, 
Wong et al.

including the use of validated standardized questionnaires of functional complications and quantitative measurements of anatomic complications (such as IIEF or the Sexual Heath Inventory for Men (SHIM) questionnaires); direction, degree angulation, and bother of penile curvature; and size, location, and reported bother of tunical scars. Higher-quality reporting in penile fracture series would improve the utility of future systematic reviews.

\section{Conclusion}

This systematic review and meta-analysis identified no statistical difference between timing of penile fracture repair (early [less than 24 hours from time of injury to presentation/ surgery] vs. delayed [greater than or equal to 24 hours]) and rates of ED and tunical scar formation. Rates of penile curvature - which did not affect sexual functioning and were thus felt to be clinically insignificant — did favour immediate repair. Although the gold standard for penile fracture is surgical repair, this review suggests that a brief delay may be acceptable in select patients. As the series analyzed in this review are primarily of low to moderate methodological quality, immediate repair for penile fracture repair should still remain the standard of care. Nonetheless, the fact that this systematic review did not find a relationship between timing of penile fracture repair and clinically significant complications warrants further investigation in this area.

Competing interests: Dr. Davies has been an advisor for Allergan, Boston Scientific, and Pfizer; and has received honoraria/grants from Allergan, Astellas, Boston Scientific, and Pfizer. The remaining authors report no competing personal or financial interests.

This paper has been peer-reviewed.

\section{References}

1. Bella AJ, Shamloul R. Addressing the barriers to optimal management of penile fracture. Can Urol Assoc J 2013;7:258-9. hittps://doi.org/10.5489/cuaj.1560

2. Yamacake KGR, Tavares A, Padovani GP, et al. Long-term treatment outcomes between surgical correction and conservative management for penile fracture: Retrospective analysis. Kor I Urol 2013;54:472-6. https://doi.org/10.4111//kju.2013.54.7.472

3. Agarwal MM, Singh SK, Sharma DK, et al. Fracture of the penis: A radiological or clinical diagnosis? A case series and literature review. Can J Urol 2009;16:4568.

4. Karadeniz T, Topsakal M, Ariman A, et al. Penile fracture: Differential diagnosis, management, and outcome. Br J Urol 1996;77:279-81. https://doi.org/10.1046/j.1464-410X.1996.86420.x

5. Gottenger EE, Wagner JR. Penile fracture with complete urethral disruption. J Trauma 2000;49:339-41. https://doi.org/10.1097/00005373-200008000-00025

6. Zargooshi J. Penile fracture in Kermanshah, Iran: Report of 172 cases. J Urol 2000;164:364-6. https://doi.org/10.1016/S0022-5347(05)67361-2

7. Zargooshi J. Penile fracture in Kermanshah, Iran: The long-term results of surgical treatment. BJU Int 2002;89:890-4. https://doi.org/10.1046/i.1464-410X.2002.02745.x
8. Kozacioglu $Z$, Degirmenci $T$, Arslan $M$, et al. Long-term significance of the number of hours until surgical repair of penile fractures. Urol Int 2011;87:75-9. https://doi.org/10.1159/000325589

9. Berlin JA. Does blinding of readers affect the results of meta-analyses? University of Pennsylvania Meta-analysis Blinding Study Group. Lancet 1997;350:185-6. https://doi.org/10.1016/S0140$6736(05) 62352-5$

10. Wright I, Cole E, Farrokhyar F, et al. Effect of preoperative hormonal stimulation on postoperative complication rates after proximal hypospadias repair: A systematic review. J Urol 2013;190:652-60. https://doi.org/10.1016/i.juro.2013.02.3234

11. Anselmo $G$, Fandella $A$, Faggiano $L$, et al. Fractures of the penis: Therapeutic approach and long-term results. Br J Urol 1991;67:509-11. https://doi.org/10.1111/j.1464-410X.1991.tb15196.x

12. Saporta L, Miroglu C, Ekinci $M$, et al. Penile fractures and our treatment policy. Int Urol Nephrol 1997;29:85-9. https://doi.org/10.1007/BF02551422

13. Cummings JM, Parra RO, Boullier JA. Delayed repair of penile fracture. J Trauma 1998;45:153-4. https://doi.org/10.1097/00005373-199807000-00032

14. Hsu G-L, Hsieh C-H, Wen H-S, et al. Curvature correction in patients with tunical rupture: A necessary adjunct to repair. J Urol 2002;167:1381-3. https://doi.org/10.1016/S0022-5347(05)65306-2

15. Wani I. Management of penile fracture. Oman Med J 2008;23:162.

16. Shetty M, Nerli R, Kamat S, et al. Penile fractures: Results of delayed repair. Indian J Urol 2004;20:123.

17. El-Assmy A, El-Tholoth HS, Mohsen T, et al. Does timing of presentation of penile fracture affect outcome of surgical intervention? Urology 2011;77:1388-91. https://doi.org/10.1016/i.urology.2010.12.070

18. Alzubaidi R. Which one is guilty in self-induced penile fractures: Marital status, culture or geographic region? A case series and literature review. J Sex Med 2012;9:329-30.

19. Tijani $\mathrm{KH}, \mathrm{Ogo}_{\mathrm{CN}}, \mathrm{Ojew}$ ola RW, et al. Increase in fracture of the penis in south-west Nigeria. Arab J Urol 2012;10:440-4. https://doi.org/10.1016/i.aju.2012.07.004

20. Zargooshi J. Sexual function and tunica albuginea wound healing following penile fracture: An 18-year followup study of 352 patients from Kermanshah, Iran. J Sex Med 2009;6:1141-50. https://doi.org/10.1111/i.1743-6109.2008.01117.x

21. Nasser TA, Mostafa T. Delayed surgical repair of penile fracture under local anesthesia. I Sex Med 2008:5:2464-9. https://doi.org/10.1111/i.1743-6109.2008.00851.x

22. Naraynsingh $V$, Ramdass MJ, Thomas D, et al. Delayed repair of a fractured penis: A new technique. Int J Clin Pract 2003;57:428-9.

23. Kibria SA, Islam MF, Bhuyan Zl. Fracture penis—a study of twenty cases. Bangladesh Med Res Counc Bull 2001;27:33-7.

Correspondence: Dr. Nathan Wong, Division of Urology, McMaster University, Hamilton, ON, Canada; nathan.wong@medportal.ca

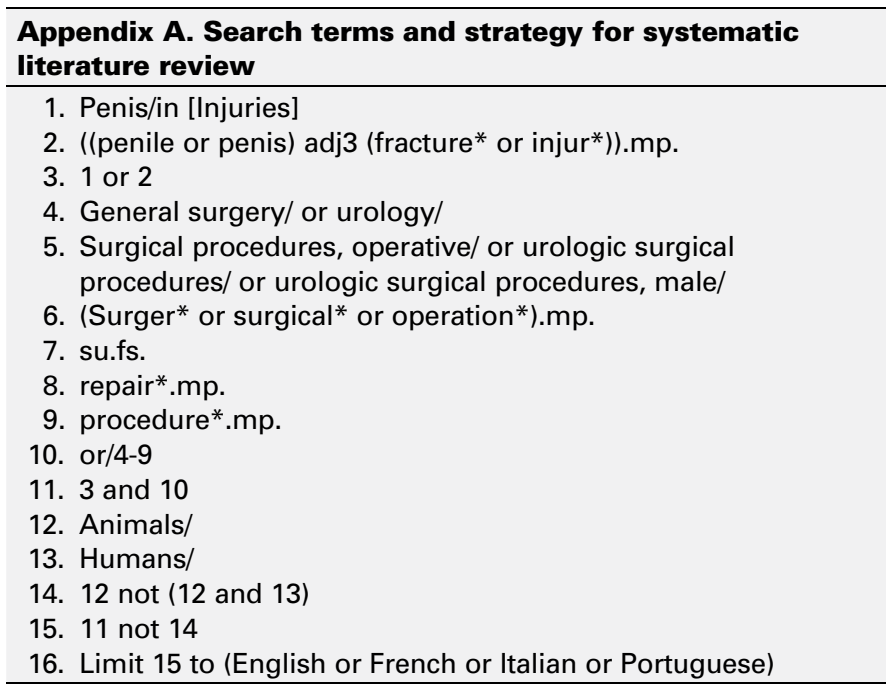

